\title{
Project Albúmina: preserving photographic memories
}

\author{
Giralt, $V^{1}$, Baleriola, $M^{2}$, Jiménez-Bolívar, $M .^{3}$, Ramos-Guaz, J.M. ${ }^{4}$, Ramírez-González, J. ${ }^{5}$ \\ ${ }^{1}$ Central ICT Services, University of Málaga, Málaga, Spain, victoriano@uma.es \\ ${ }^{2}$ Central ICT Services, University of Málaga, Málaga, Spain, baleriola@uma.es \\ ${ }^{3}$ Image Technology Centre, University of Málaga, Málaga, Spain, mmjimenez@uma.es \\ ${ }^{4}$ Central ICT Services, University of Málaga, Málaga, Spain, jose-manuel.ramos-guaz@uma.es \\ ${ }^{5}$ Image Technology Centre, University of Málaga, Málaga, Spain, jramirezg@uma.es
}

\section{Keywords}

Digital archives, e-preservation, photographies, archiving software, virtual exhibitions.

\section{ABSTRACT}

The present work presents a joint proposal from University of Málaga Image Technology Centre (CTI) and Central ICT Service (SCI), to create a digital photographic archive for the former. Such archive will contribute to the preservation of valuable memories supported on photographies by allowing easier access to the wider society. The University of Málaga Image Technology Centre (CTI-UMA) is an audio-visual producing facility aimed at photo and video-graphic and multimedia production. The photographic archive has half a million photographs, both from historic collections from the late nineteenth century and the 1980's and from the service daily work.

The project aim was to facilitate the creation of a standards based electronic archive of the digital version of the originals and, at the same time, allowing for an easy creation of on-line exhibitions based on web quality versions of the original images, catering both to researchers and professionals and to the general public. The archive was supposed to be at the same time scalable and affordable. Any code used or produced for the project had to be open source, so other institutions could easily make use of our work for their photographic archives.

The results are encouraging, as the project, in its present status, has allowed for the classification of over fifty thousand originals, increasing the productivity of the archival team fivefold, and the creation of three virtual exhibits, with their physical counterparts.

\section{PROJECT DEFINITION}

The project has several objectives:

- Describing the collections according to international archiving standards, easing research use and international exchange.

- Designing a management system that allows for the creation of a digital archive that encompasses from high definition digital through web quality images.

- Creation of services based on both the archive information and the digital material, like virtual exhibitions or allowing the general public to improve the documentation of the archived material.

Archival description is a complex task, but the ICA (International Council of Archives) has defined several international normative frameworks for the task. Such norms have been implemented into an open source software web application called ICA-AtoM (ICA Access to Memory). We have used this application for the project archive description tasks. It is a multilingual application that allows for a lot of normalised information to be attached to the photograph descriptions (ISAD), like authority and context (ISAAR-CPF), function (ISDF) and centres (ISDIA), as well as other descriptors, controlled vocabularies, taxonomies or links to places.

The most complex task for the IT team was designing a storage management system that could cater to the needs of all involved users and scale with the needs and loads of the system. The system manages the whole cycle from digital photograph upload to the storage systems, through the cataloguing functions supported by ICA-AtoM, through reuse of the material for creating virtual 
exhibitions that can be published as a web site. The system scales from a single machine installation on a laptop up to a multi-server deployment storing the digitised photographs on an SAN, like the one used by the University of Málaga.

\section{DEVELOPMENT}

The project started as a quest for a better and faster way for cataloguing the historical photographic archive of CTI, composed of almost half a million originals. There were standards described in the paper but we could not find any open source software, or for that matter, closed source, that could fit the needs. The team's first intention was to create the whole system from scratch, but that would require time and resources we did not have. After some research, we found ICA-AtoM. It was not perfect, but the catalographic implementation was really thorough. The problem was in the general public facing side of the system: it was simply too complex for simple mortals. Moreover, it had no notion of virtual exhibitions or an easy way to digest batches of digitised materials.

Our team is well versed in the Python Django web framework that allows us to produce solid applications in short time. So, we developed an application with two purposes: to ease the input of the originals into the system and produce virtual exhibits. As the exhibits had the most time pressing schedule, this is the part that was developed first.

\section{PRESENT STATUS}

The system is already in production with over fifty thousand photographs catalogued and has been used for setting up three virtual exhibitions. It can automatically insert registers into ICA-AtoM from batches of originals uploaded to the storage servers, for latter review and completion by human cataloguers. The uploading interface allows the user to input basic information common to the whole batch. All cataloguing functions are managed through ICA-AtoM.

Once the materials have been catalogued, it is possible to mount virtual carousels from ICA-AtoM searches, and those carousels arranged to form a virtual exhibit that will be presented through the exhibits interface in users' browsers.

\section{FUTURE}

We have found that both the code and the database design of ICA-AtoM is a bit of a nightmare that together with a lack of interest for contributions by the not much helpful authors and, finally, the news that it may no longer be open source, have prompted us to start our own design of that piece of the system. One of the problems is the use of a structured SQL database shoehorned into storing non- or semi-structured objects. All code produced by the University of Málaga in this project will be made available as open source.

\section{REFERENCES}

ICA website (2013). International Council of Archives. Retrieved May 20th, 2013. from: http://www.ica.org/

ICA-AtoM website (2013). International Council of Archives Access to Memory. Retrieved May 20th, 2013, from: http://www.ica-atom.org/

Ministerio de Cultura (2012). Modelo conceptual de descripción archivística y requisitos de datos básicos de las descripciones de documentos de archivo, agentes y funciones. Retrieved May 20th, 2013.

from: http://www.mcu.es/archivos/docs/NEDA_MCDA_P1_P2_20120618.pdf

Ministerio de Cultura (2010). Norma para la elaboración de puntos de acceso normalizados de instituciones, personas, familias, lugares y materias en el sistema de descripción archivística de los archivos estatales. Retrieved May 20th, 2013. from:

http://www.mcu.es/archivos/docs/Novedades/Norma_puntos_acceso2010.pdf 


\section{AUTHORS' BIOGRAPHIES}

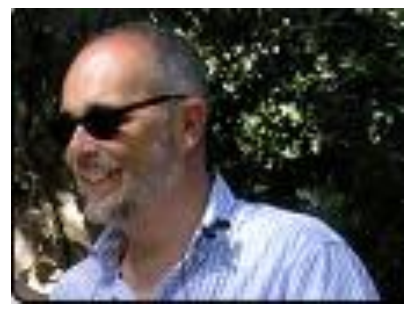

V. Giralt is the systems manager for the University of Málaga. Graduated as an MD from the University of Málaga in 1986, and became a member of the University IT team in 1987 as a programmer. Has worked as a programmer for the University and systems administrator both for the International University of Andalusia (1990-1995) and the University of Málaga. Chairs the technical committee of the Confia identity federation for the Andalusian public universities and the Groningen Declaration Executive Committee. Member of the steering committee of RS3G EUNIS task force, member of the European Committee for Academic Middleware, member of the TERENA EMC2 task force, acting as co-chair during 2012, member of the RedIRIS identity task force, member of the SSEDIC EU expert network on electronic identity.

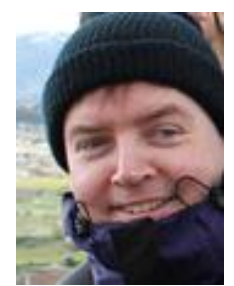

M. Baleriola has a degree in Computer Science Engineering and also a Master in Software Engineering and Artificial Intelligence at the University of Málaga. He started writing books about ethical hacking and Linux in the 90's. In early 2000's he landed in web programming and near 2008 he met Django and fell in love with Python. Nowadays he is working as a sysadmin and developer in Central ICT Services of the University of Málaga. He was one of the developers of a virtual microscope software presented as TERENA 2009 and EUNIS 2009 that obtained the III Educational Innovation Award at the University of Málaga in 2010.

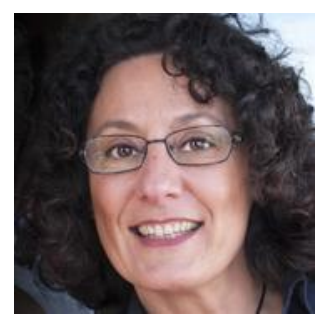

M. Jiménez-Bolivar holds a degree in Documentation from Universitat Oberta de Catalunya and a postgraduate degree in Digital Documentation from Barcelona Pompeu Fabra University. Coordinates the photographic archive and documentation area of the University of Málaga Imaging Technology Centre. She is responsible for systematising the CTI photographic archive organisation. She has also recovered and documented CTI historic materials using digital photography techniques. These materials have been used for organising exhibitions both in by $\mathrm{CTI}$ and other institutions. She has designed the documentation aspects of project Albumina.

J.M. Ramos-Guaz holds a degree in Mathematics from the University of Málaga and started work in $\mathrm{SCl}$ as a programmer in 1977, becoming a systems analyst in 1984, and chief of the systems and communications unit in 1992. José Manuel has a loving taste for ancient photography, specially that dedicated to late XIX century Málaga, and a deep experience in storage systems design, making him a perfect match for mentoring the project and an inspiration for the team. He is also, in his own terms, a decent chess player.

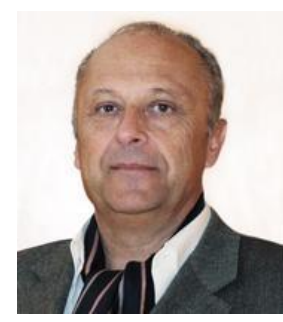

J. Ramírez-González holds a Ph.D. in History and a Masters degree in History and Geography from the University of Málaga. Director of the University Imaging Technology Centre, of many research and dissemination (exhibitions and publications) projects on photographic archives and collections restoration. Has published papers on photographies about Málaga. He is the Director of project Albumina. 